\title{
Erratum to: Occurrence of organotin compounds in river sediments under the dynamic water level conditions in the Three Gorges Reservoir Area, China
}

\author{
Jun-Min Gao ${ }^{1,3} \cdot$ Ke Zhang $^{1,3} \cdot$ You-Peng Chen ${ }^{2} \cdot$ Jin-Song Guo $^{1,2} \cdot$ Yun-Mei Wei ${ }^{1,3}$. \\ Wen-Chao Jiang ${ }^{1,3} \cdot$ Bin Zhou $^{1} \cdot$ Hui Qiu ${ }^{1}$
}

Published online: 12 July 2015

(C) Springer-Verlag Berlin Heidelberg 2015

Erratum to: Environ Sci Pollut Res (2015) 22:8375-8385

DOI 10.1007/s11356-014-3986-1

The original version of this article contains a mistake.

The $1^{\text {st }}$ corresponding Author should be Jun-Min Gao.

The online version of the original article can be found at http://dx.doi.org/ 10.1007/s11356-014-3986-1.

Jun-Min Gao

gao-junmin@126.com

$\triangle$ You-Peng Chen

ypchen@cigit.ac.cn

1 Key Laboratory of the Three Gorges Reservoir Region's

Eco-Environment, Ministry of Education, Chongqing University, Chongqing 400045, China

2 Key Laboratory of Reservoir Aquatic Environment, Chongqing Institute of Green and Intelligent Technology, Chinese Academy of Sciences, Chongqing 400714, China

3 National Centre for International Research of Low-carbon and Green Buildings, Chongqing University, Chongqing 400045, China 